\title{
Comparison of Measured and Modelled Residual Stresses in a Welded P91 Steel Pipe Undergoing Post Weld Heat Treatment
}

\author{
Anas H Yaghi', Thomas H Hyde², Adib A Becker², Wei Sun², Wu Wen², \\ Gabrielle Hilson $^{3 *}$, Sarinova Simandjuntak ${ }^{4}$, Peter EJ Flewitt ${ }^{3,5}$, Martyn J Pavier ${ }^{6}$ and \\ David J Smith ${ }^{\text {*** }}$ \\ ${ }^{1}$ The Manufacturing Technology Centre (MTC), Ansty Park, Coventry CV7 9JU, UK \\ ${ }^{2}$ Department of Mechanical, Materials and Manufacturing Engineering, University of Nottingham, \\ Nottingham NG7 2RD, UK \\ ${ }^{3}$ Interface Analysis Centre, University of Bristol, Bristol BS2 8BS, UK \\ ${ }^{4}$ School of Engineering, Faculty of Technology, University of Portsmouth, Portsmouth PO1 3DJ, UK \\ ${ }^{5} \mathrm{H}$ H Wills Laboratory, Department of Physics, University of Bristol, Bristol BS2 1TN, UK \\ ${ }^{6}$ Department of Mechanical Engineering, University of Bristol, Bristol BS8 1TH, UK
}

*Now at Rolls Royce Deutschland

**This paper is dedicated to the memory of the late Professor David Smith.

\begin{abstract}
The process of fusion arc welding of steel pipes in power generation plants induces residual stresses which may be detrimental to the integrity and endurance of plant pipelines. P91 is high-grade steel used in the construction of pipelines carrying hot steam at high pressure, conditions which cause creep during service. Welded P91 pipes are usually subjected to postweld heat treatment (PWHT) to mitigate the magnitude of residual stresses and temper the material, hence improving its resistance to creep. In this paper, the finite element (FE) method of modelling residual stresses due to PWHT in a circumferentially butt-welded P91 pipe is presented. The PWHT hold temperature is $760^{\circ} \mathrm{C}$. The paper describes the X-Ray Diffraction (XRD) and Deep-Hole Drilling (DHD) experimental techniques and how they are applied to measure residual stresses in the welded P91 pipe after PWHT. The material property data, necessary for the FE simulation of PWHT, has been obtained from stress-relaxation tests on P91 uniaxial tensile specimens at $760^{\circ} \mathrm{C}$. Good agreements have been achieved between the results of the FE method and the two sets of experimentally-measured residual stresses.
\end{abstract}

Corresponding author:

Prof. A.A. Becker, Faculty of Engineering, University Park, Nottingham, NG7 2RD UK

Email: ezaab21@exmail.nottingham.ac.uk 


\section{Highlights}

- Finite Element simulations of residual stresses in welded 91 pipes are presented

- Post-weld heat treatment (PWHT) incorporated in the analysis

- FE residual stresses are compared with two sets of experimental measurements

- Good agreements achieved between FE predictions and experimental data

\section{Keywords}

P91 Steel Pipe, Finite Element, Residual Stress, X-Ray Diffraction, Deep-Hole Drilling, Post Weld Heat Treatment 
Welded steel pipes are an essential component in the construction of steam pipelines in fossilfuel power generation plants. The pipelines carry hot steam at high pressure and are expected to endure creep over many years of service. The maximum allowable steam temperature and pressure values, for the safe operation of the plants, are governed by the integrity and creep resistance of the welded pipes under operating conditions. Modern superheat plants are increasingly pushing the limits of temperature and pressure higher to increase plant efficiency, and hence reduce carbon-dioxide emission. For that purpose, high-grade creep-resistant P91 steel was introduced in power plants in Japan and the UK in 1989. Since then, particularly in the last decade, the popularity of P91 plant pipeline components has been on the increase in several countries worldwide.

The process of welding P91 steel, necessary for the joining of plant pipes, involves extreme thermal cycles which affect the microstructure and mechanical behaviour of the material. The heat affected zone (HAZ) in the pipe material, near the weld region, is considered to be most susceptible to creep-damage and Type-IV cracking. The extreme thermal cycles also induce residual stresses in the welded pipes which, at some places, can be of the same order as the material yield stress. Such high residual stresses can be detrimental to the integrity and mechanical performance of the welded components. It is usual, therefore, to subject the welded P91 pipes to post-weld heat treatment (PWHT) to substantially reduce the magnitude of residual stresses and also to temper the material to obtain higher creep ductility and better creep resistance. The effects of PWHT on mechanical properties of and residual stresses have been investigated by many researchers [1-3]. Olabi et al [1] have reported that the PWHT reduces the residual stresses by about $70 \%$ and improves the toughness by about $15 \%$ for a low-carbon structural steel. The residual stress distributions in a P91 steel weld have been studied by neutron diffraction before and after the PWHT [2], where the maximum residual stresses are reported being reduced from about $600 \mathrm{MPa}$ to about $120 \mathrm{MPa}$. Dong et al [3] presented a study on the mechanisms of residual stress relief in PWHT and claims that the most dominant mechanism is creep strain induced stress relaxation, while plastic strain has limited effects. An engineering method for estimating residual stress reduction, relating material types, PWHT temperature and pipe wall thickness, has also been proposed.

In this paper, the finite element (FE) method is applied to model the mitigating effect of PWHT on residual stresses in a circumferentially butt-welded P91 steel pipe, typically found as a structural component in steam pipelines in power plants. The FE results, obtained from the two-dimensional (2D) axisymmetric simulation are validated by comparing them with experimentally obtained stresses. The FE simulation to determine residual stresses in the welded pipe prior to PWHT is described. The process of PWHT is simulated using the FE method, and hence, the final residual stress field after applying PWHT is numerically determined. The FE simulation assumes that the model undergoes creep during the three-hour hold time of the PWHT procedure and that the process of creep obeys Norton creep law. The material creep constants necessary for the simulation have been obtained from stress-relaxation tests conducted on P91 uniaxial tensile specimens. The FE simulation and resulting residual stresses are described in detail in this paper. Experimental measurements of residual stresses following PWHT are also described. The measurements have been obtained using two experimental techniques, namely, X-Ray Diffraction (XRD) and Deep-Hole Drilling (DHD). The FE simulated residual stresses after PWHT have been validated by comparing them to the experimental measurements. The effect of PWHT on residual stresses are presented and discussed. 


\section{Experimental Procedure}

The P91 pipe was initially cut into two halves and machined to the required shape. They were then welded by joining the ends with P91 filler weld material. Residual stresses were then measured by two experimental techniques, XRD and DHD. The welded pipe was then subjected to PWHT and the residual stresses were measured again, after PWHT, using the same experimental techniques. The measured residual stresses were used to validate the numerically determined residual stresses in the modelled welded pipe.

\subsection{Welded Pipe Specifications and PWHT}

The welded P91 pipe was produced by joining two halves of a P91 pipe using a similar P91 weld metal. The butt weld consists of 73 circumferentially deposited weld beads. The welded pipe had an outside diameter of $290 \mathrm{~mm}$, a wall thickness of $55 \mathrm{~mm}$ and a total length of 520 $\mathrm{mm}$. The geometry and overall dimensions of the multi-pass weld are shown in Figure 1. The weld sequence is also shown in the figure. The weld was deposited by manual metal arc (MMA) welding, with an approximate welding-electrode average speed of $175 \mathrm{~mm} / \mathrm{minute}$ and a preheat temperature of $200^{\circ} \mathrm{C}$. The interpass temperature was maintained between $200^{\circ} \mathrm{C}$ and $300^{\circ} \mathrm{C}$, and, at the end of welding, the pipe was allowed to cool down to room temperature. The circumferential position of the start of each weld pass was varied from pass to pass. The first weld bead (root bead) protrudes at the bore of the pipe by approximately $1.5 \mathrm{~mm}$. The last layer of weld beads, forming the weld crown, protrudes beyond the outside surface of the pipe by about $2 \mathrm{~mm}$. The weld crown was machined off by grinding to make it possible to take XRD measurements at the outside surface of the weld and the adjacent pipe (parent) material. The welded pipe was subjected to PWHT, after the removal of the weld crown, in a vacuum furnace at $760^{\circ} \mathrm{C}$ for a holding period of three hours. The heating and cooling rates of the PWHT procedure were 100 and $46^{\circ} \mathrm{C}$ per hour, respectively.

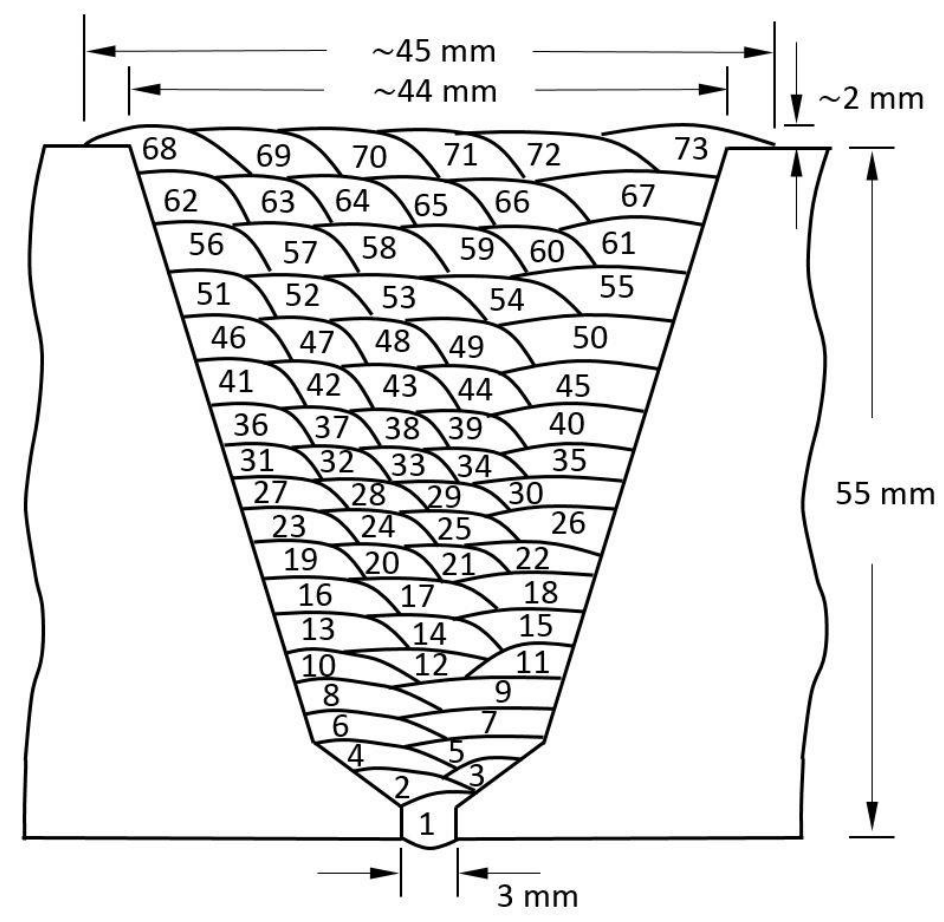

Figure 1 Sketch of weld bead sequence showing overall weld dimensions 
The chemical composition of the P91 parent metal is shown in Table 1. The weld has been produced by depositing Babcock Type $M$ filler rods of $4 \mathrm{~mm}$ diameter with a similar composition to that of the parent metal. The overall microstructure of the parent P91 pipe is tempered martensite. In the weld metal, individual beads contain combinations of columnar grains and grain-refined equiaxed regions arising from heat cycles as subsequent beads are deposited [4]. The microstructure in weld regions is martensitic with a small proportion of delta ferrite. In the parent metal, the HAZ extends over a distance of approximately $3.5 \mathrm{~mm}$ away from the weld. A cross-sectional macro-image of the weld region, HAZ and adjacent parent material is shown in Figure 2. The microstructural regions in the weld can also be seen in that figure.

Table 1 Chemical composition of the P91 steel pipe [5]

\begin{tabular}{|c|c|c|c|c|c|c|c|c|c|c|c|c|}
\hline Element & $\mathrm{C}$ & $\mathrm{Ni}$ & $\mathrm{Mn}$ & $\mathrm{Cr}$ & $\mathrm{Mo}$ & $\mathrm{V}$ & $\mathrm{Si}$ & $\mathrm{P}$ & $\mathrm{S}$ & $\mathrm{Al}$ & $\mathrm{Nb}$ & $\mathrm{Fe}$ \\
\hline Weight (\%) & 0.1 & 0.28 & 0.47 & 8.66 & 0.95 & 0.212 & 0.31 & 0.012 & 0.002 & 0.014 & 0.071 & bal. \\
\hline
\end{tabular}

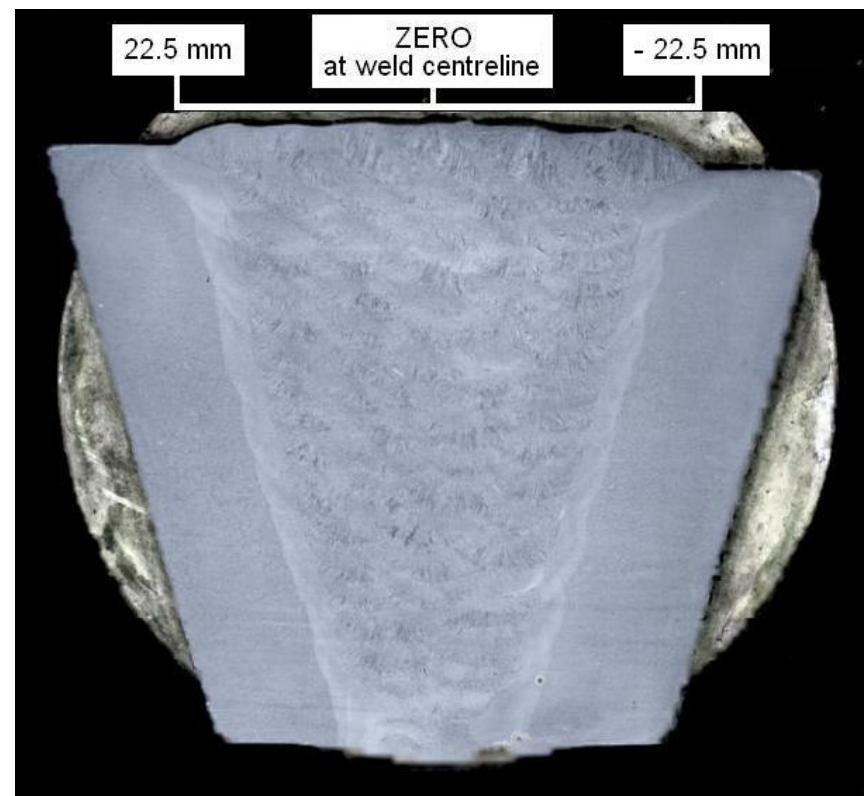

Figure 2 Macro-image of a cross-section of the weld, HAZ and adjacent pipe material

\subsection{X-Ray Diffraction (XRD)}

XRD was used to measure the residual macro-stresses on the outside surface of the pipe and weldment. A portable computer controlled X-ray diffractometer provided flexibility to map stresses across the weld metal, HAZ and parent pipe in directions along and parallel to the axis of the pipe. Details of the X-ray diffractometer and the technique have been described elsewhere [6]. The measurements were made using $\mathrm{Cr} \mathrm{K}_{\alpha} \mathrm{X}$-radiation to produce a diffraction peak at $2 \theta \approx 156^{\circ}$ from the $\{112\}$ planes. An incident collimator of $1 \mathrm{~mm}$ diameter provided an appropriate spatial resolution for mapping the strains which were converted to macrostresses using conventional elasticity theory and a pre-determined elastic constant for the $\{112\}$ crystal planes. Stresses were measured to an accuracy of $\sim 10 \mathrm{MPa}$.

Prior to PWHT in a vacuum furnace at $760^{\circ} \mathrm{C}$ for three hours, the weld crown was removed from the weld cap to create a flat surface. The surface was then mechanically lapped and electro-polished using an electrolyte containing $5 \% \mathrm{HCl}$ in water (by volume). This procedure ensured that any stresses introduced by the original cap preparation were removed. Following the vacuum heat treatment, the surface oxide thickness was less than $\sim 1 \mu \mathrm{m}$. Previous work 
has shown that it is possible to make realistic measurements with oxides of up to 5 to $10 \mu \mathrm{m}$ being present [7].

\subsection{Deep-Hole Drilling (DHD)}

The DHD procedure to measure residual stresses started with a $3.175 \mathrm{~mm}$ reference hole gun drilled through the wall of the pipe [8]. The diameter of the hole was measured at points through the pipe using an air probe technique. Next, the residual stresses around the hole were relaxed by electro-discharge machining to leave a stress-free $10 \mathrm{~mm}$ diameter trepanned core with the reference hole at its centre. Finally, the diameter of the reference hole was remeasured. The change in the diameter of the hole may be related to the residual stresses present in the pipe. DHD residual stress measurements were made before PWHT at the centre of the weld, at the edge of the weld and in the parent material. Subsequently, PWHT measurements were made at the centre and edge of the weld. In this paper, only the weld centreline results are presented, but more details of these measurements are provided elsewhere [7].

\section{$3 \quad$ Finite Element Simulation}

The FE simulation has been conducted by generating the FE model and running a thermal analysis followed by a sequentially-coupled structural analysis. The FE model consists of generating an FE mesh of the complete welded pipe, specifying the required material property data and prescribing initial and boundary conditions. The welding process of the pipe is then simulated by running thermal and sequentially-coupled (the output data of the former analyses was taken as the input data for the following analyses) structural analyses, determining residual stresses induced by welding. The procedure of PWHT is then simulated by running further thermal and sequentially-coupled structural analyses, determining residual stresses following the mitigating effect of PWHT. The FE simulation of the welded pipe, throughout the reported work, has been performed using 2D axisymmetric elements, which can simulate the quasisteady-state of the actual welding process without allowing for the welding starting and stopping effects. A 2D axisymmetric simulation can be performed with a relatively fine FE mesh, which can predict residual stresses with sufficient accuracy around the circumference of the welded pipe at locations away from the starting and stopping points [4]. A threedimensional (3D) FE simulation, detecting the effects of starting and stopping of welding around the circumference, would have a much coarser 3D FE mesh, significantly compromising the accuracy of results, even with a comparatively larger size FE model (more degrees of freedom), requiring prohibitively large computing time.

\subsection{FE Mesh}

The complete FE mesh for the pipe and weld is generated from the start, before any analyses take place. This allows the material to deform, at the same time, maintain compatibility between pipe and weld elements. If the mesh representing the weld were added later, at the time of deposition, the deformed pipe elements would not maintain displacement compatibility with the deformation-free weld elements. 


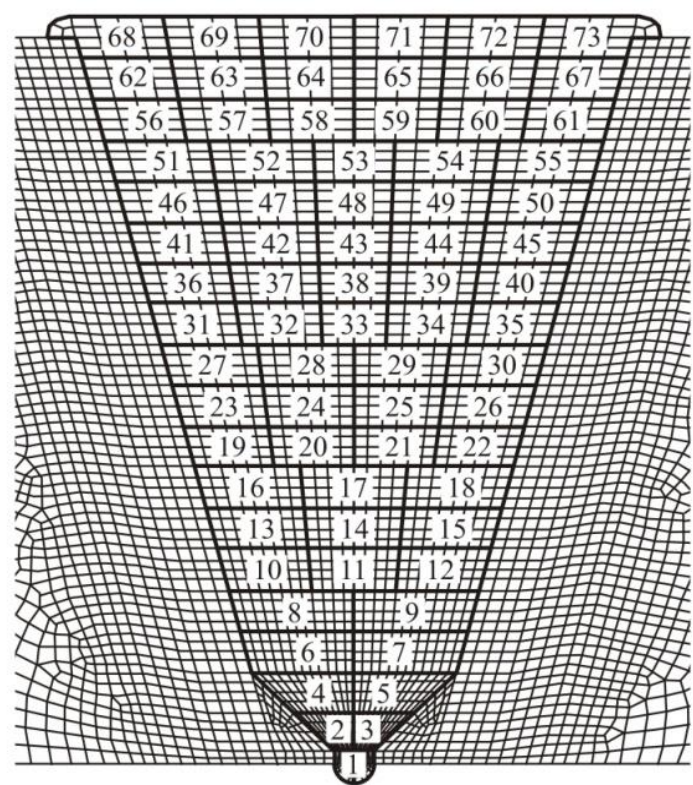

Figure 3 FE mesh at the weld region showing the FE weld pass sequence

The deposition of the weld is simulated during the thermal and structural analyses by adopting a technique termed "element birth" $[9,10]$. The FE mesh of the whole welded pipe model contains 5127 elements and 15632 nodes. The mesh at the weld region is presented in Figure 3 , depicting the weld sequence in the FE model, which is identical to that of the actual welding procedure. Each weld bead is considered to be a pass in the FE mesh, making the number of passes in the FE model equal to the number of beads in the actual weld. Each pass in the mesh consists of a discrete number of elements. The root bead and weld crown are modelled to protrude by $1.5 \mathrm{~mm}$ and $2 \mathrm{~mm}$ respectively.

\subsection{Residual Stress Simulation Prior to PWHT}

The simulation of the evolving stress field during the PWHT of the welded pipe is based on initial residual stresses determined by simulating the process of welding of the pipe. The simulation of welding and the resulting residual stresses are described in detail in a previous publication [4]. There, the FE simulation, performed using the commercial software Abaqus [11], comprises a thermal analysis and a sequentially-coupled structural analysis, adopting a solid mechanics approach. The thermal analysis simulates the heat delivered by the welding electrode arc by applying a uniformly-distributed heat flux to each weld pass, determining the temperature history of the FE model. The structural analysis uses the temperature history as input data, determining the evolution of stresses during welding, including residual stresses, by relating stresses to temperatures via the temperature-dependent coefficient of linear thermal expansion of P91 steel. The structural analysis takes into consideration the effects of solidstate phase transformations, as detailed elsewhere [4]. The determined FE residual stresses due to welding, prior to PWHT, have been validated by comparing them to experimentally measured residual stresses, obtained by applying the XRD and DHD techniques. The experimental measurements have been taken after grinding the weld crown off, which has been simulated in the FE structural analysis by removing the weld crown elements after the completion of welding. FE and XRD residual hoop and axial stresses are plotted in Figure 4 against distance along a straight line on the outside surface of the pipe in the axial direction, with zero distance coinciding with the weld centreline (WCL). FE and DHD residual hoop and axial stresses are plotted in Figure 5 against distance along the WCL, from the outside surface to the bore. Good correlation between the FE results and the experimental measurements is shown in both figures. 


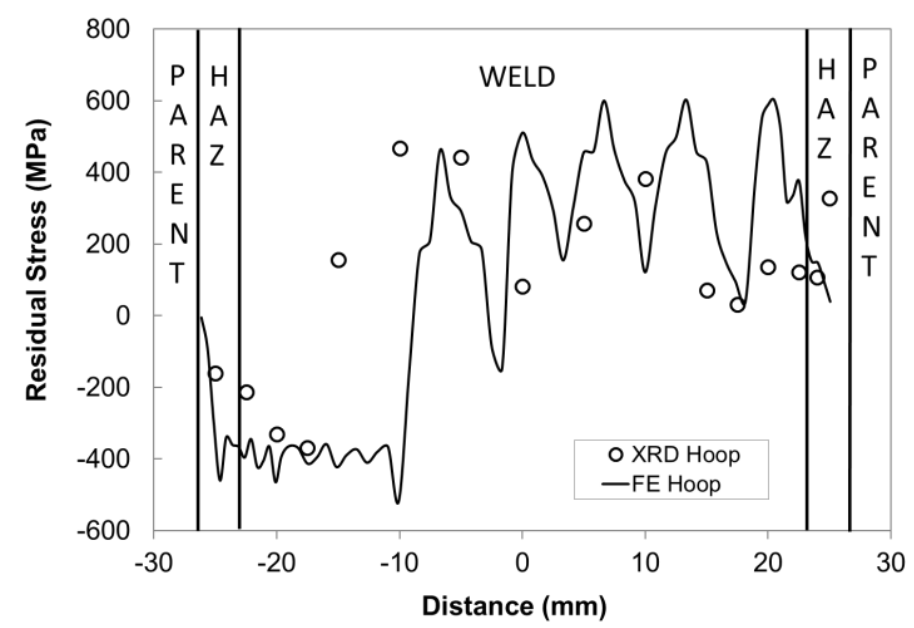

(a)

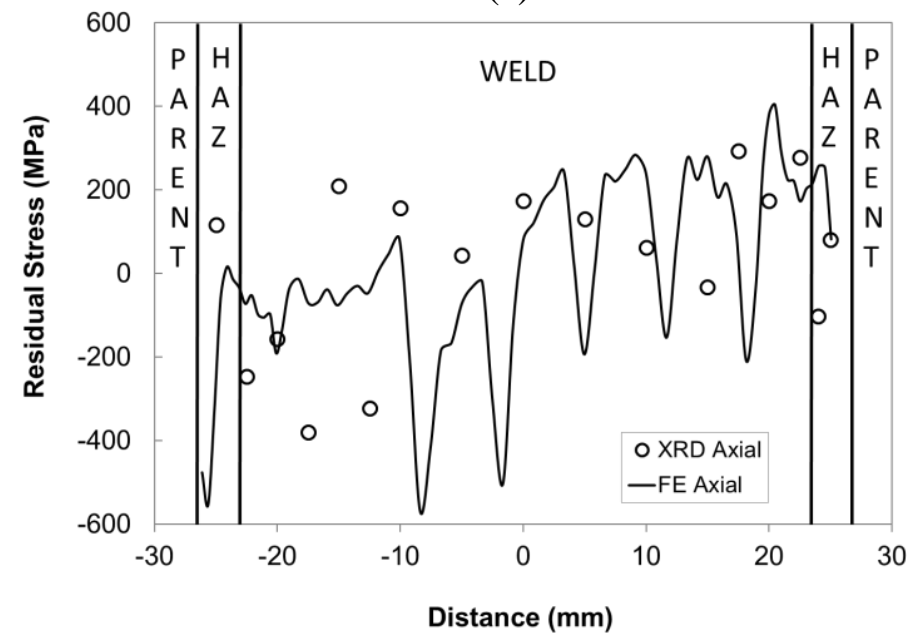

(b)

Figure $4 \quad$ FE and XRD residual (a) hoop and (b) axial stresses at the outside surface against distance measured from the weld centre with the negative distance on the side of the last weld bead.

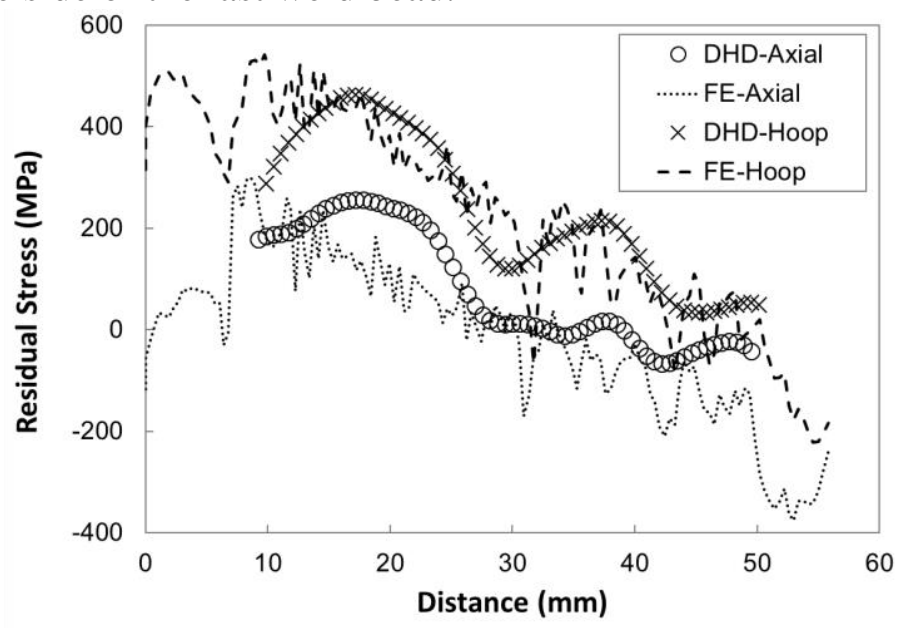

Figure $5 \quad$ FE and DHD residual hoop and axial stresses against distance measured from the outside surface through the thickness along the WCL. 


\subsection{PWHT Simulation}

Following the removal of the weld crown, the P91 steel pipe was subjected to PWHT in a vacuum furnace at $760^{\circ} \mathrm{C}$ for a holding period of three hours. PWHT not only causes residual stresses to relax, it also tempers any untempered martensite. The relaxation of residual stresses during PWHT can be simulated by assuming that the steel exhibits creep and obeys Norton creep law at the holding temperature of $760^{\circ} \mathrm{C}$ [12], given in the multi-axial form by

$$
\frac{d \varepsilon_{i j}^{c}}{d t}=\frac{3}{2} A \sigma_{e q}^{n-1} S_{i j}
$$

where $d \varepsilon_{i j}^{c} / d t$ represents the creep strain rate components, $S_{i j}$ represents the deviatoric stresses, $\sigma_{e q}$ is the equivalent stress, and $A$ and $n$ are non-zero material constants [5]. The constants $A$ and $n$ for P91 steel have been determined from stress relaxation testing of the material. The simulation of the PWHT process has then been made possible by inserting the determined values of $A$ and $n$ into the input file of the FE structural analysis. The structural analysis is sequentially-coupled to the thermal analysis, which simulates the PWHT heating and cooling cycles by prescribing a temperature gradient at the model boundary, inducing heat flow until the required temperatures are reached. The most relevant material property data used in the simulation are depicted in Figure 6.

Stress relaxation in the FE simulation takes place due to creep and also due to the reduction in the values of the yield stress and elastic modulus of the material as the temperature goes up to $760^{\circ} \mathrm{C}$, causing a plastic redistribution of the residual stresses. Creep during heating and cooling is considered to be negligible [12]. The element type in the thermal analysis is eightnoded quadratic axisymmetric diffusive heat transfer continuum solid quadrilateral, and in the structural analysis it is eight-noded axisymmetric stress/displacement continuum solid biquadratic quadrilateral with reduced integration [11].

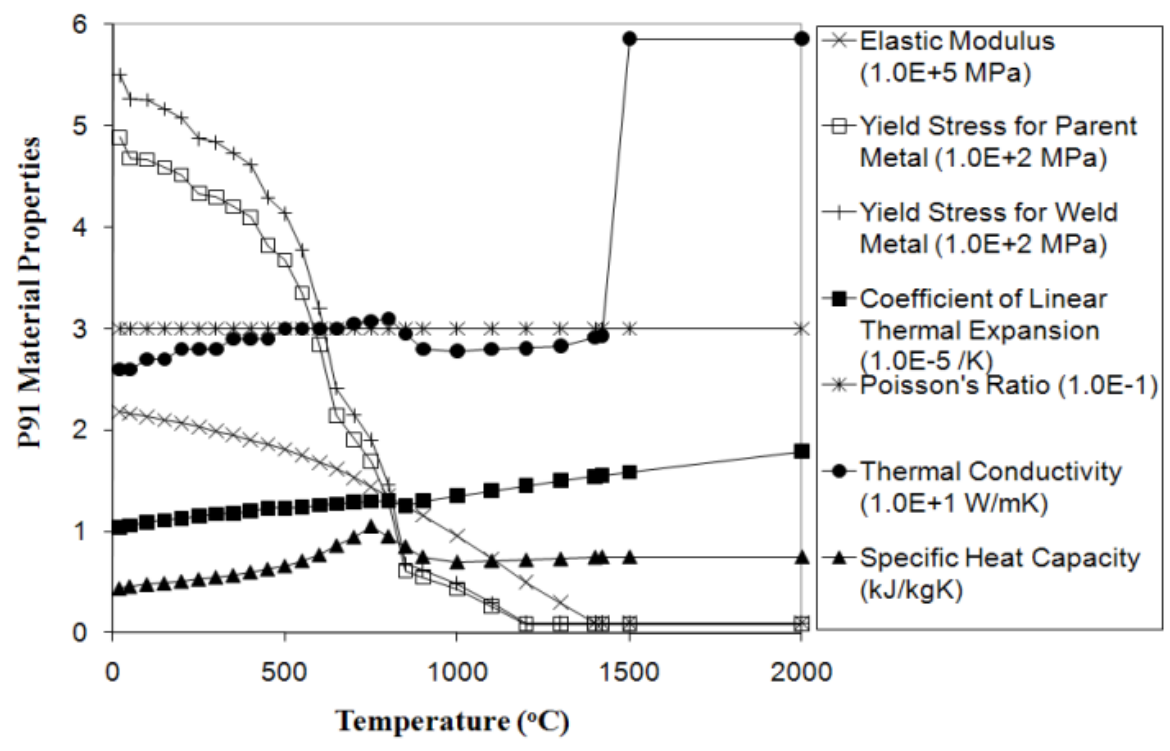

Figure 6 Mechanical and thermal material properties for P91 steel against temperature [10]

\subsection{Stress Relaxation Testing}

Three stress relaxation tests were conducted on $\mathrm{P} 91$ steel at $760^{\circ} \mathrm{C}$, using pipe parent material. Ridged uniaxial tensile specimens, each with a total length of $130 \mathrm{~mm}$ and gauge length and diameter of $50 \mathrm{~mm}$ and $10 \mathrm{~mm}$ respectively, were heated to $760^{\circ} \mathrm{C}$ in a furnace, then loaded in 
a Mayes axial-loading servo-hydraulic universal testing machine under uniaxial tension with an approximate strain rate of $4 \times 10^{-5} \mathrm{~s}^{-1}$, and then allowed to stress-relax under constantly-held strain for three hours. Norton creep law, in the uniaxial form, is given by

$$
\frac{d \varepsilon}{d t}=A \sigma^{n}
$$

where $d \varepsilon / d t$ is the creep strain rate and $\sigma$ is the uniaxial stress. An additional specimen was tested to failure under uniaxial tensile loading at $760^{\circ} \mathrm{C}$ in order to obtain the elastic modulus of the material, which is required for the derivation of $A$ and $n$ from the stress relaxation test data. It has been assumed that the stress relaxation behaviour is the same for the parent material and weld metal.

The rate of change of stress with time in a uniaxial tensile stress relaxation test under constant temperature and strain, assuming Norton-Bailey creep law and time-hardening behaviour, and for a constant stress/strain ratio, can be expressed as

$$
\mathrm{d} \sigma \mathrm{dt}=-m E A^{\frac{1}{m}} \sigma^{\frac{n}{m}}\left(\frac{\sigma_{0}-\sigma}{E}\right)^{\frac{m-1}{m}}
$$

where $\mathrm{m}$ is a constant (less than 1 when there is primary creep), $\mathrm{E}$ is the elastic modulus (stress/strain) and $\sigma_{0}$ is the maximum stress at the start of relaxation [13]. If Norton creep law is assumed $(\mathrm{m}=1)$, the above equation becomes

$$
\mathrm{d} \sigma \mathrm{dt}=-E A \sigma^{n}
$$

which in turn can be used to determine $\mathrm{A}$ and $\mathrm{n}$ from the stress relaxation test results.

From the stress-strain behaviour of the specimen taken to failure under uniaxial tensile loading, it is found that the proportionality between stress and strain is maintained up to about $38 \mathrm{MPa}$ (proportionality limit), above which the stress-strain curve increasingly deviates from a straight line; $0.2 \%$ yield stress is found to be $105 \mathrm{MPa}$, above which plastic deformation becomes increasingly evident. The ratio of stress/strain has to be constant to be able to use Equation (4) to derive $\mathrm{A}$ and $\mathrm{n}$. A constant stress/strain ratio is maintained up to a stress of $38 \mathrm{MPa}$, and therefore the maximum stress in the stress relaxation tests used to determine $\mathrm{A}$ and $\mathrm{n}$ has been limited to $38 \mathrm{MPa}$.

Three stress relaxation tests have been conducted. The uniaxial tensile stress for each test is plotted against time in Figure 7. The initial stress (just before relaxation) for tests 1,2 and 3 is 31.1 MPa, 37.4 MPa and 63.1 MPa respectively. For the material, the stress/strain ratio remains constant up to $38.0 \mathrm{MPa}$ (stress-strain proportionality limit). Therefore, only the data of tests 1 and 2 are used to determine A and $n$ from Equation (4): the gradient of the curves in both tests, $\mathrm{d} \sigma / \mathrm{dt}$, together with the corresponding stress value, $\sigma$, are substituted in Equation (4) to find $\mathrm{A}$ and $\mathrm{n}$; from the stress-strain relationship of the material, the elastic modulus $(\mathrm{E})$ is found to be $75 \mathrm{GPa}$, which is also substituted in the equation. A and $\mathrm{n}$ have been found to be equal to $2.371 \times 10^{-17}$ ( $\sigma$ in $\mathrm{MPa}$ ) and 8 respectively. Furthermore, stress has been calculated by integrating Equation (4) with respect to time. The calculated stress is plotted against time in Figure 7, which demonstrates that the calculated stress and the stress values in tests 1 and 2 converged to the same value after three hours of relaxation. 


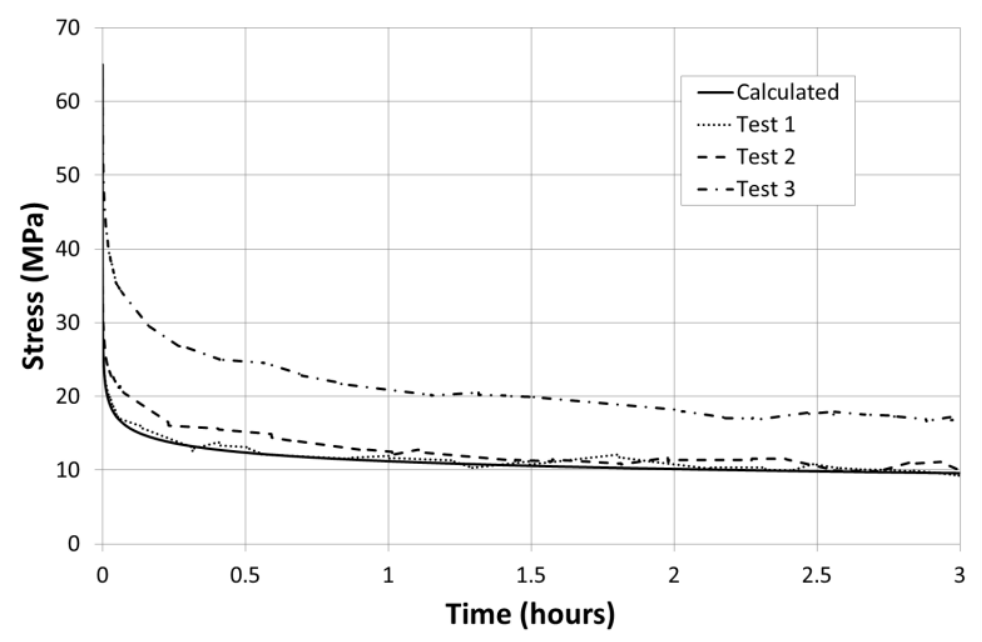

Figure $7 \quad$ Stress relaxation curves from P91 steel uniaxial tensile tests

\subsection{Residual Stresses after PWHT}

Residual stresses have been determined by the FE simulation at the completion of the PWHT process. The residual hoop and axial stress contours are presented in Figures 8 and 9. The stress contours in the two figures demonstrate that the stresses in general remain within \pm 20 $\mathrm{MPa}$. Extrapolation and interpolation of stresses from the FE integration points to the nodes of the mesh causes sharp oscillations in the stress values, giving exaggerated stress peak values at some nodes. In plots of stress against distance, this exaggeration can be resolved and the stress profile can be smoothed out by applying adjacent-point averaging.

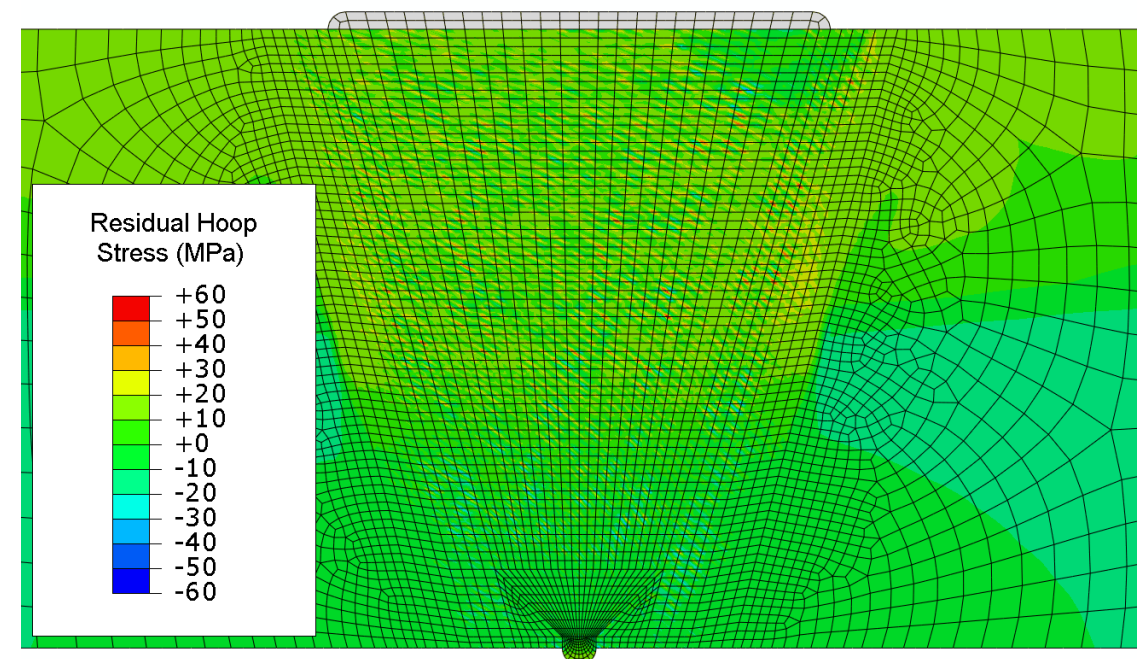

Figure 8 FE residual hoop stress contours after PWHT. 


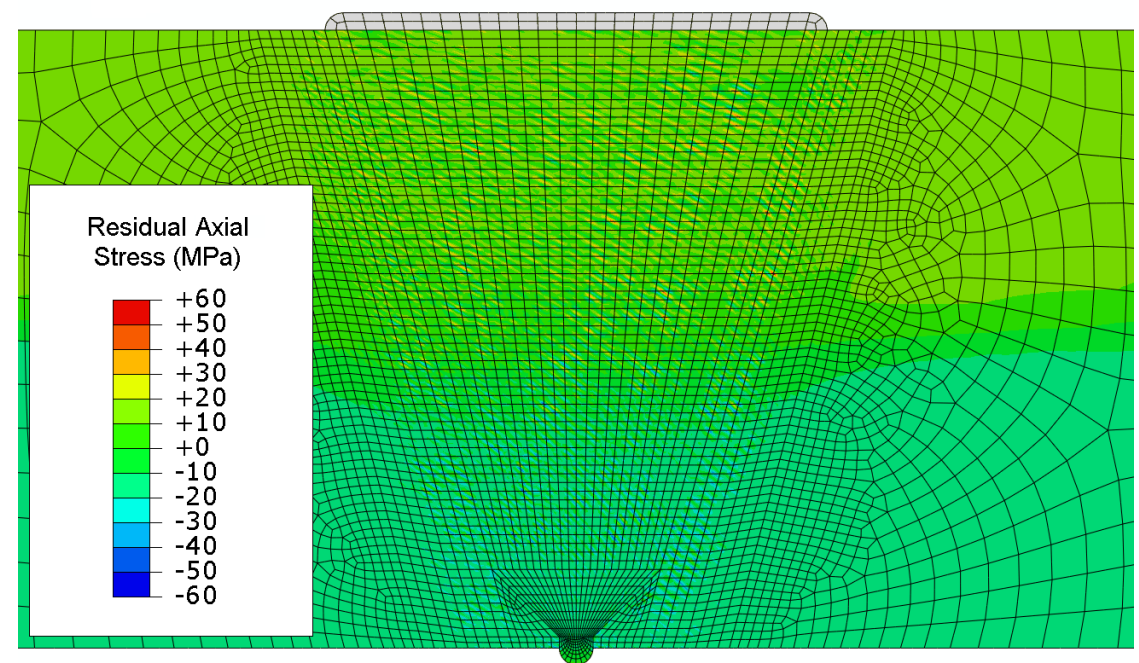

Figure $9 \quad$ FE residual axial stress contours after PWHT.

\section{Comparison between Experimental and FE Results}

The FE residual stress results after PWHT for the P91 welded pipe are validated by comparing them to the XRD and DHD experimental measurements. The FE residual stresses are compared with the XRD results along a line on the outside surface of the pipe parallel to the axis of the pipe. The FE results are compared with the DHD measurements along the WCL, starting near the outside surface and going towards the bore in the radial direction. The comparisons will be discussed in more detail in the sections 4.1 and 4.2.

\subsection{FE Residual Stresses versus XRD Measurements}

FE predictions and XRD measurements of hoop and axial residual stresses are presented in Figure 10. The residual stresses are plotted along a line on the outside surface of the pipe in the axial direction, going from the HAZ, through the weld, to the HAZ on the other side. The zero position coincides with the centreline of the weld. Figure 10 also shows the locations of the weld and HAZ boundaries. Residual stresses predicted by the FE method have substantially reduced in magnitude compared to those determined before PWHT, which are presented in Figure 4. The XRD measurements of residual stresses have also reduced in magnitude due to PWHT, although not to the same degree as the FE predictions; however, most XRD measurements fall within a $\pm 50 \mathrm{MPa}$ band. This result may be attributed to weld bead variations, which cause increased fluctuation in the magnitude of XRD measured stresses. In addition, the small gradient of the $2 \theta$ versus $\sin ^{2} \psi$ curve for these measurements means that an error in an individual measurement becomes more significant in evaluating the residual stress. 


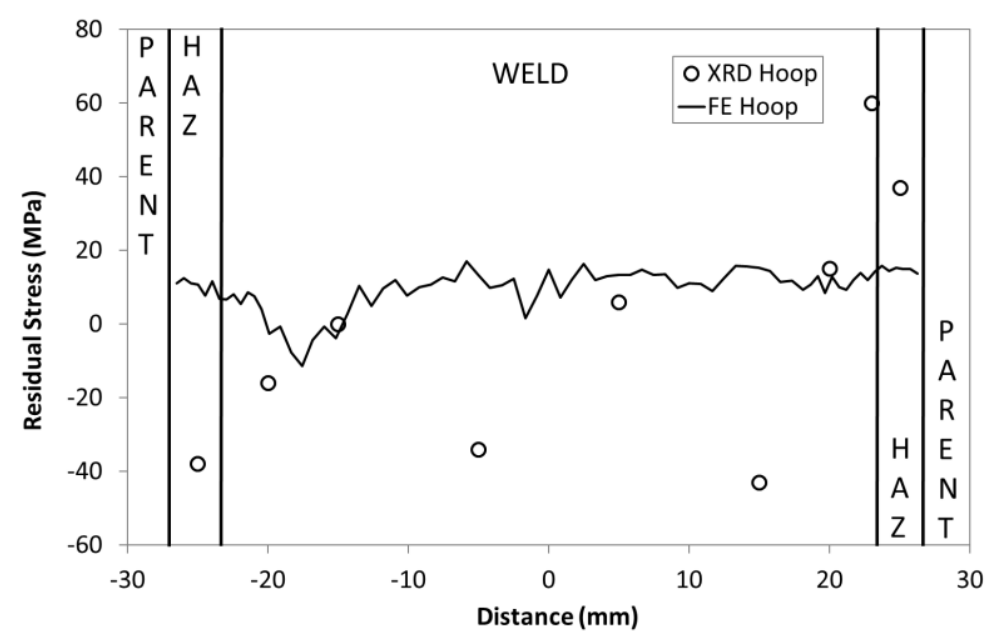

(a)

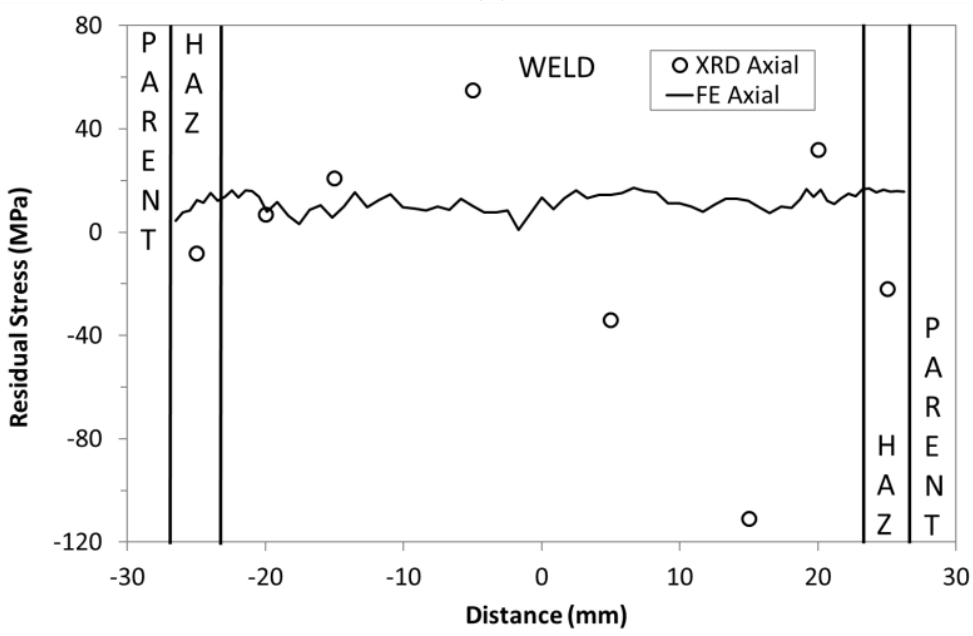

(b)

Figure $10 \quad$ FE and XRD residual (a) hoop and (b) axial stresses, after PWHT, at the outside surface against distance measured from the weld centre with the negative distance on the side of the last weld bead.

\subsection{FE Residual Stresses versus DHD Measurements}

FE predictions are compared with DHD measurements in Figure 11. The results are plotted in a radial direction along the WCL, starting from the outside surface and going towards the bore. The FE results in Figure 11 are for those nodes along the WCL. Since the DHD measurements are effectively an average of the residual stresses for points within the $10 \mathrm{~mm}$ diameter trepanned core, Figure 12 shows a revised comparison where the FE results are the average of nodal values in a $10 \mathrm{~mm}$ wide strip of the model. The comparison of FE predictions with DHD measurements is generally very good. 


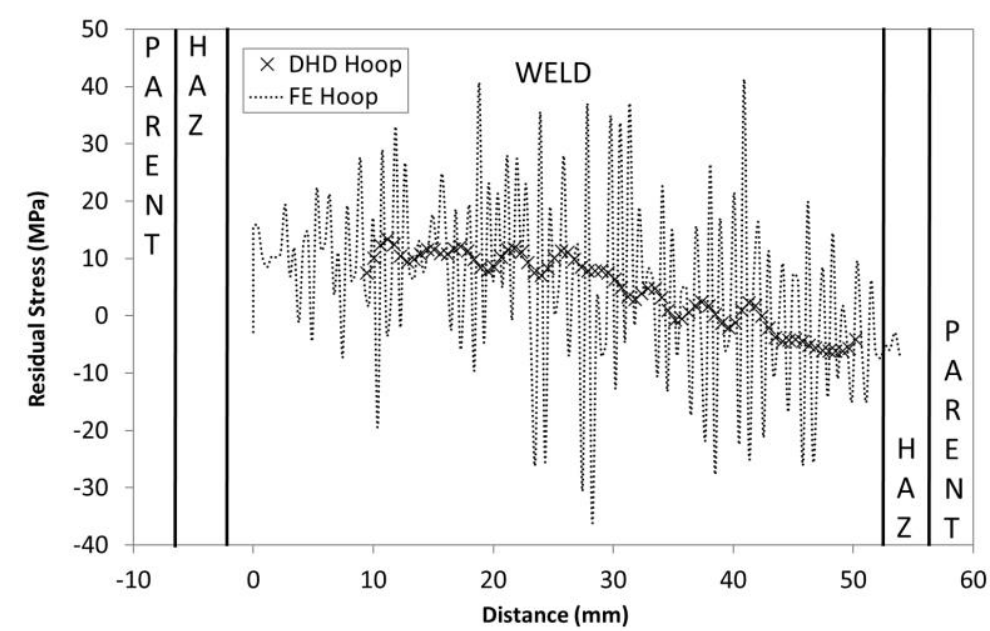

(a)

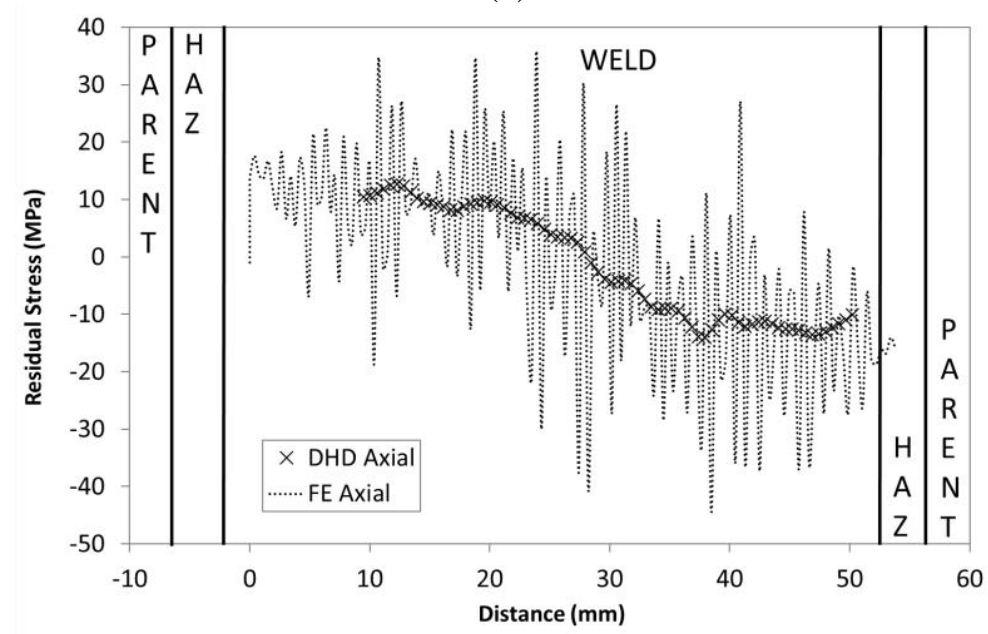

(b)

Figure $11 \quad$ FE and DHD residual (a) hoop and (b) axial stresses, after PWHT, against distance measured from the outside surface through the thickness along the WCL.

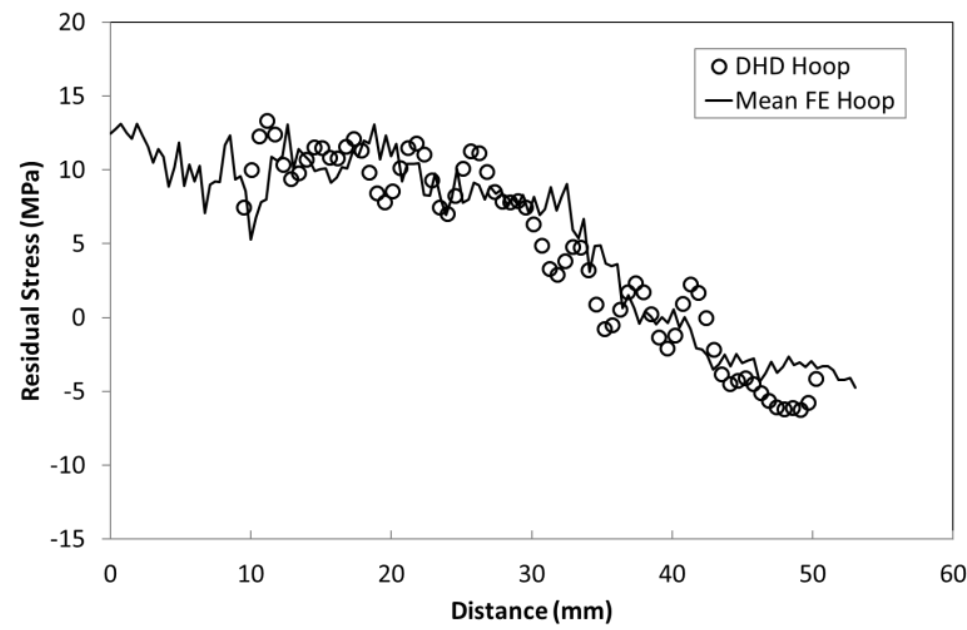

(a) 


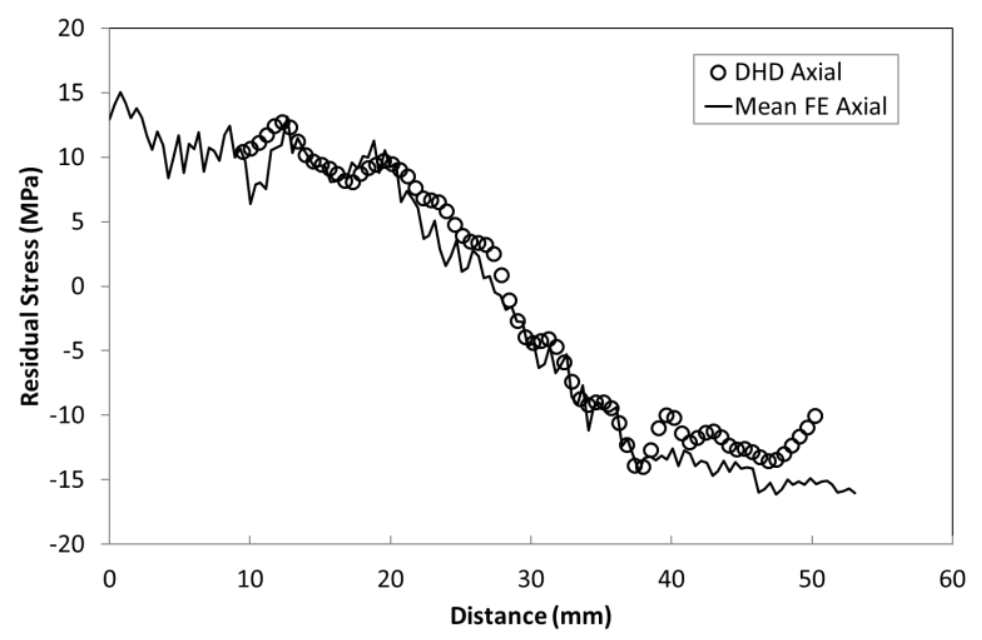

(b)

Figure 12 FE (mean) and DHD residual (a) hoop and (b) axial stresses, after PWHT, against distance measured from the outside surface through the thickness along the WCL.

\section{$5 \quad$ Discussion}

High-grade steel pipes in power generation plants, responsible for carrying steam at high temperature and pressure, are usually joined together by fusion arc welding. Extreme thermal cycles during welding give rise to residual stresses, which can have similar magnitude to the yield stress of the material. Large tensile residual stresses are considered to be detrimental to the integrity of the welded pipes and can limit their life expectancy during service. PWHT, which not only mitigates residual stresses, but also tempers the material, increasing its ductility and enhancing its creep strength, therefore is a vital process for welding of any high temperature steel pipes.

Nevertheless, structural integrity assessments, such as those invoking the R6 procedure [14], require the residual stresses to be included. Since these contribute directly to the calculation of stress intensity factors for postulated defects, even small values can have a significant influence on the assessment, particularly because the working stresses themselves also tend to be of low magnitude. As a consequence, it is important to have a realistic value for stresses remaining in components after post weld heat treatment. The present work has demonstrated that the stresses are of low magnitude, but that it is necessary to compare experimental measurements with numerical predictions to provide confidence.

In this paper, residual stresses induced by the fusion arc welding, to join two halves of a P91 steel pipe together, were numerically simulated by applying the FE method. The numerically determined residual stress field has then been subjected to PWHT by assuming that Norton creep law is obeyed during PWHT holding time at $760^{\circ} \mathrm{C}$. The creep material constants, required for the FE input file, have been determined by conducting stress relaxation testing on uniaxial tensile specimens of the pipe material. The residual stress field after PWHT is thus numerically determined. Residual stresses in the FE model reduce in magnitude during PWHT not only due to creep at the holding temperature but also due to the reduction in the yield stress of the material as the temperature rises, resulting in substantial plastic redistribution of large stresses.

It can be seen from the residual stress graphs and contours presented in this paper that PWHT has a very large mitigating effect on the magnitude of residual stresses. Peak residual stresses 
prior to PWHT have a similar magnitude to the yield stress of the material (sometimes even higher due to strain hardening). Peak magnitudes, which are as high as $600 \mathrm{MPa}$ approximately, substantially decrease during PWHT to a value below $20 \mathrm{MPa}$. There is a corresponding decrease in the magnitude of the micro-residual stress with PWHT, as indicated by the decrease in the full-width half-height of the X-ray diffraction peaks. Typically, these peaks decrease from a width of approximately $2 \theta=3^{\circ}$ to $2 \theta=1^{\circ}$ [15].

The residual stress field, after PWHT, obtained from the FE simulation of the welded P91 pipe, has been validated by comparing it to measurements taken by the XRD and DHD experimental techniques. This comparison shows that adopting Norton creep law in the FE simulation to model creep during PWHT holding time for such a component provides valid stress results. It is worth noting, however, that the creep material constants, required by the FE simulation, must be derived carefully, as described earlier in the paper, to obtain valid stress results. The material creep constants should be derived from stress relaxation tests, which, for P91 steel, must have an initial (maximum) stress not exceeding $38 \mathrm{MPa}$. Furthermore, in the reported work, the FE method has been applied to a welded pipe having a thick wall, in which case less plasticity is expected to take place in comparison to pipes with thin walls. Plasticity has a significant influence on creep behaviour, and therefore the validity of the stress results in applying the FE method is thus far valid for thick-walled modelled components [16].

\section{Conclusions}

- The FE simulation of the circumferential fusion arc butt-welding and PWHT of a thickwalled P91 steel pipe has been described.

- $\quad$ The FE simulation of PWHT assumes that creep during the holding time obeys Norton creep law, and therefore the material creep constants, required by the FE model, have been experimentally obtained from the stress relaxation testing of P91 steel specimens.

- $\quad$ PWHT has been shown to have a very large mitigating effect on residual stresses, reducing peak stresses from around $600 \mathrm{MPa}$ to a magnitude below $20 \mathrm{MPa}$.

- $\quad$ FE residual hoop and axial stresses, after PWHT, have been validated by comparing them to experimental measurements obtained from the XRD and DHD techniques.

\section{ACKNOWLEGEMENT}

We would like to acknowledge the support of The Energy Programme, which is a Research Councils UK cross council initiative led by EPSRC and contributed to by ESRC, NERC, BBSRC and STFC, and specifically the Supergen initiative (Grants GR/S86334/01 and EP/F029748) and the following companies; Alstom Power Ltd., Doosan Babcock, E.ON, National Physical Laboratory, Praxair Surface Technologies Ltd, QinetiQ, Rolls-Royce plc, RWE npower, Siemens Industrial Turbomachinery Ltd. and Tata Steel, for their valuable contributions to the project.

$\mathrm{Wu}$ Wen, Adib Becker and Wei Sun would like to acknowledge the support of the EU Horizon 2020 project on Generation IV Materials Maturity Programme (Grant 755269). 


\section{REFERENCES}

1. Olabi, A.G. and Hashmi, M.S.J., "The effect of post-weld heat-treatment on mechanical-properties and residual-stresses mapping in welded structural steel," Journal of Materials Processing Technology, vol. 55, pp. 117-122, 1995.

2. Paddeaa, S., Francis J.A., Paradowskac, A.M., Boucharda P.J. and Shibli, I.A., "Residual stress distributions in a P91 steel-pipe girth weld before and after post weld heat treatment," Materials Science and Engineering A, vol. 534, pp. 663-672, 2012.

3. Dong, P., Song, S. and Zhang, J., "Analysis of residual stress relief mechanisms in post-weld heat treatment," International Journal of Pressure Vessels and Piping, vol. 122, pp. 6-14, 2014.

4. Yaghi A. H., T. H. Hyde, A. A. Becker, W. Sun, G. Hilson, S. Simandjuntak, P. E. J. Flewitt, M. J. Pavier, and D. J. Smith, "A comparison between measured and modelled residual stresses in a circumferentially butt-welded P91 steel pipe," ASME Journal of Pressure Vessel Technology, vol. 132, pp. 011206-1 to 011206-10, 2010.

5. Yaghi A. H., T. H. Hyde, A. A. Becker, and W. Sun, "Finite element simulation of welding and residual stresses in a P91 steel pipe incorporating solid-state phase transformation and post-weld heat treatment," Journal of Strain Analysis, vol. 43, pp. 275-293, 2008.

6. McDonald E. J., K. R. Hallam, W. Bell and P. E. J. Flewitt, "Residual stresses in a multi-pass CrMoV low alloy ferritic steel repair weld," Materials Science and Engineering, A, vol. 325, pp. 454-464, 2002.

7. Hilson G, Simandjuntak S, Flewitt PEJ, Hallam KR, Pavier MJ and Smith DJ, "Spatial Variation of Residual Stresses in a Welded Pipe for High Temperature Applications", Int. J. Pressure Vessels and Piping, vol. 86 (11), pp. 748-756, 2009.

8. George D., Kingston E. and Smith D. J., "Measurement of through-thickness stresses using small holes," Journal of Strain Analysis, vol. 37(2), pp. 125-139, 2002.

9. Brickstad B. and B. L. Josefson, "A parametric study of residual stresses in multipass butt-welded stainless steel pipes," International Journal of Pressure Vessels and Piping, vol. 75, pp. 11-25, 1998.

10. Yaghi A. H., T. H. Hyde, A. A. Becker, J. A. Williams, and W. Sun, "Residual stress simulation in welded sections of P91 pipes," Journal of Materials Processing Technology, vol. 167, pp. 480-487, 2005.

11. ABAQUS User Manual, version 6.7, Hibbitt, Karlsson \& Sorensen, Inc, 2007.

12. Berglund D., H. Alberg, and H. Runnemalm, "Simulation of welding and stress relief heat treatment of an aero engine component," Finite Elements in Analysis and Design, vol. 39, pp. 865-881, 2003.

13. Becker A. A., "Understanding Non-linear Finite Element Analysis," Textbook published by NAFEMS, Glasgow, ISBN 1-874376-35-2, 2001, Chapter 3, page 77.

14. British Energy. Assessment of the integrity of structures containing defects. R6 Revision 4. British Energy Ltd, April 2004.

15. Hilson G., "The inter-relationship between surface condition and near surface residual stresses in engineering components," PhD thesis, University of Bristol, 2008.

16. Yaghi, A.H., Hyde, T.H., Becker, A.A. and Sun, W. "Finite Element Simulation of a Welded P91 Steel Pipe Undergoing Post Weld Heat Treatment", J. Science and Technology of Welding and Joining, Vol. 16, No. 3, pp. 232-238, 2011. 